\title{
Editorial
}

\section{Water: An International and Interdisciplinary Scientific Open Access Journal}

\section{John Bridgeman}

Editor-in-Chief of Water, School of Civil Engineering, The University of Birmingham, Edgbaston, Birmingham, B15 2TT, UK; E-Mail: j.bridgeman@bham.ac.uk; Tel. +44 (0)121 414 5145;

Fax: +44 (0)121 4143675

Received: 14 August 2009 / Published: 14 August

That water is the world's most precious natural resource cannot be in doubt. Increasing demands for water due to growing population, increasing urbanization and industrial development exemplify its vital role in human life. Water touches us all, from the commercial private sector which either generates or uses the product potable water; through national and international government agencies (policy makers and regulators who attempt to maintain and improve our environment, whilst also making provision for the effective and safe treatment and distribution of potable water, and the collection, treatment discharge of our wastewater); to the general public whose lives depend upon the availability of sufficient quality and quantity.

With increasing global change pressure, settlements, villages, towns and cities of the future will experience difficulties in the efficient management of water resources which are becoming increasingly scarce and unreliable in both quality and quantity. In order to meet these challenges, the global water community of practitioners, researchers, policy formers and governments has an important role to play in the definition and solution of impending problems.

Climate change (whether anthropogenically-induced or not) and its potential effects on aquatic ecosystems, resource availability and resilience in response to flooding; energy availability and chemical consumption add to the uncertainties which are inherent in projections of our future environment, and such uncertainties cause difficulties when developing water management strategies which are sufficiently robust to accommodate them. Without question, ensuring the provision of a safe and sufficient supply of water to global populations, whilst improving and maintaining our resilience to water-related natural threats, and preserving natural habitats are key, fundamental challenges for the global water community in the short, medium and long terms.

The need for the efficient management and use of water resources is clear but the scientific understanding, management structure, legislation and technology required for such efficient use are 
complex. There is a demand in all parts of the world for specialists able to understand the complex role of water in the natural environment and in modern society and who are able to provide effective management and utilization of the resources.

Consequently, any work which seeks to develop our underpinning knowledge of water; its chemical, physical and biological characteristics, its occurrence, behaviour and responses, is of tremendous value to us as individuals and societies. Events, issues and discussions move on apace. To reflect this, there exists the need for dissemination routes which are faster than the more traditional paper-based journals. Nowadays, papers which address key, fast-moving issues cannot be left for 1218 months before publication. It is important therefore that all avenues are explored and exploited for the rapid and effective dissemination of information arising regarding this most vital of resources for the delivery and implementation of wide-ranging impacts and benefits.

The new online, open-access journal Water has been launched to provide comprehensive coverage of ecology and the management of water resource systems. While retaining the highest levels of peer review, Water is addressing this dissemination need. High quality, innovative, pioneering and relevant papers are invited from the broad water community on all aspects of the water environment, both natural and engineered. All papers will be subject to a rigorous peer review process and then published online, providing the shortest possible turnaround time for work to be brought to stakeholders' attention. In addition, the Editorial Board recognizes the value of depth of coverage as well as breadth, and so no restrictions are placed on the length of submissions, giving authors the opportunity to share data and results in as much detail as possible.

The Editorial Board sees Water as an exciting innovation in the publication of water-related research. We are fully committed to the success of the Journal and want to drive it to a position where it is recognized as a premier outlet for high quality, leading edge research. Key to that success is, of course, its readership and potential authors. On behalf of the Editorial Board, I invite you to submit your original work, review papers and suggestions for Special Issues to Water and share your contributions online with the global water community. I look forward to receiving your contributions in this exciting time for water resource management.

(C) 2009 by the authors; licensee Molecular Diversity Preservation International, Basel, Switzerland. This article is an open-access article distributed under the terms and conditions of the Creative Commons Attribution license (http://creativecommons.org/licenses/by/3.0/). 